\title{
Simulation of constructed wetland performance using the advection diffusion equation
}

\author{
V. Popov ${ }^{1}$, S. Ahmed ${ }^{1,2} \&$ M. Idris Qureshi ${ }^{3}$ \\ ${ }^{1}$ Wessex Institute of Technology, Environment Fluid Mechanics, \\ Ashurst Lodge, Southampton, UK \\ ${ }^{2}$ Department of Civil Engineering, Faculty of Engineering \& Technology, \\ Jamia Millia Islamia, Jamia Nagar, New Delhi-25, India \\ ${ }^{3}$ Department of Applied Sciences \& Humanities, \\ Faculty of Engineering \& Technology, Jamia Millia Islamia, \\ Jamia Nagar, New Delhi-25, India
}

\begin{abstract}
The advection diffusion equation with variable coefficients was used to predict the performance of a subsurface constructed wetland (SSCW) treatment plant. The effect of evapo-transpiration on the velocity of flow and change of rate of biodegradation kinetics with the length of flow was considered. The differential equation was solved using the Frobenius method. The model was validated on experimental results from a pilot plant in Indian climatic conditions. The data used in this work were obtained from various hydraulic and BOD loadings. Records of biochemical oxygen demand (BOD) concentrations at inlet, outlet and intermediate levels through various stages of the treatment process over eighteen months were used for calibration of the model. The results of the model show that it is an efficient and a robust tool for prediction of the waste-water treatment performance of a constructed wetland.
\end{abstract}

Keywords: mathematical modeling, constructed wetland, model studies, biochemical oxygen demand.

\section{Introduction}

Wetlands are considered as low cost alternatives for treating municipal, industrial, and agricultural effluents. Constructed wetlands (CWs) may be 
classified as surface flow marshes, vegetated subsurface flow beds, submerged aquatic bed and floating leave aquatics [1]. This new developing technology may offer a low cost and low maintenance option for domestic wastewater treatment, which is especially suitable for developing countries [2-4].

The proper operation and control of constructed wetland wastewater treatment plant (CWWWTPs) is receiving increasing attention because of the rising concern about environmental issues and the growing importance of sustainable and natural wastewater treatment. Improper design and operation of a CWWWTP have serious environmental and public health implications, as its effluents may contaminate the receiving water body, causing severe aquatic pollution and spreading various water borne diseases. For proper design and assessment of quality of non-conventional wastewater treatment and to conserve the receiving water bodies reliable prediction of effluent from $\mathrm{CW}$ is necessary. A better control can be achieved by developing a mathematical tool for predicting the plant performance based on past observations of certain key parameters. However, modeling of performance of $\mathrm{CW}$ is a difficult task due to the complexity of the processes involved. This paper presents predictive models based on a linear, variable second order differential equation. The impact of evapo-transpiration, which is quite significant in tropical and sub-tropical region on the horizontal velocity of flow, is considered. The change in the contact time with decrease in velocity will affect the performance of constructed wetland. First time dynamic behaviour of biodegradation decay rate was studied and incorporated in the simulation model. It has been observed by many researchers that the biodegradation decay rate apart from temperature also depends on quality of effluent i.e., BOD quantity. The quality of organic waste also plays a very significant role on the rate of biodegradation decay.

The developed simulation model incorporating above mentioned important parameters is applied to a pilot plant study of constructed wetland in India. The developed model has been found to perform consistently. Using this model, the planner and decision-maker can easily make an assessment of the expected plant effluent, given the quality of the influent waste stream.

\section{Experimental set up and monitoring CW (pilot plant)}

The experimental set-up which was used in this study is shown in Fig. 1. Unit A and unit B have coarse sand and fine sand respectively as filler matrix. Both were planted with Phragmites australis. Different hydraulic loading starting from $28 \mathrm{1} / \mathrm{m}^{2} /$ day to $98 \mathrm{1} / \mathrm{m}^{2} /$ day, were used in these experiments. The $\mathrm{BOD}_{5}$ loading of the pilot plant was also varied from $45 \mathrm{mg} / 1$ to $1580 \mathrm{mg} / \mathrm{l}$, so that the pilot plant can be tested for a wide range of data. Flow meters were provided before the inlet zone to record the average flow rate of total quantity of wastewater in each bed. All precautions were taken for equal distribution of wastewater in each of the $\mathrm{CW}$ beds. Five different triplicate samples, including three intermediate ones, were collected for a set of parameters. Intermediate samples were collected from intermediate ports at down stream distances of $3.2 \mathrm{~m}, 4.2 \mathrm{~m}$, and $5.2 \mathrm{~m}$ 
respectively. Acrylic sheets of $45 \mathrm{~cm}$ height were embedded up to $30 \mathrm{~cm}$ in the soil filter at inlet zone to avoid any over flow conditions in CWS.

To assess the performance of various parameters and impact of change in operational parameters such as hydraulic loading and organic loading, the beds have been set at a particular operation for a minimum of 15 days so that proper acclimatization could take place. Effluent samples were collected daily, during last five days of experimental series from inlet and outlet chambers from each bed. Intermediate samples for $\mathrm{pH}$, TSS, TDS, BOD and COD were also collected from downstream distances of $3.2 \mathrm{~m}, 4.2 \mathrm{~m}$ and $5.2 \mathrm{~m}$ respectively. All analysis was conducted in accordance with the Standard Methods for the Examination of Water and Wastewater APHA, 1998 [5].

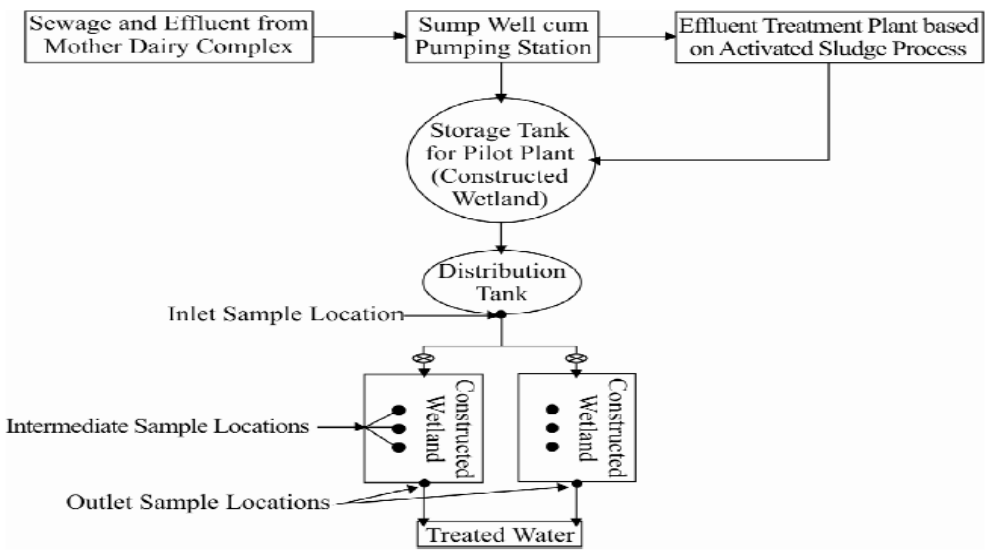

Figure 1: $\quad$ Experimental set-up used in the study.

\section{Mathematical modelling}

\subsection{Flow}

Ideal plug flow is generally assumed in the analysis and modeling of constructed wetlands. It has been observed by many researchers that plug flow conditions are seldom found in the constructed wetland treatment systems. The actual flow condition that occurs in practice can be more accurately modelled as first order kinetics and number of complex mix reactors in series [1-6].

\subsection{Bio-decay rate}

The removal rate of $\mathrm{BOD}$ in the wetlands and in facultative lagoons is proportional to the organic loading imposed on the system. The bio-decay rate constant is found to increase with the increase in organic loading. The bio-decay rate obtained by analysis of input and output BOD data leads to low and constant bio-decay rate ie $\mathrm{K}_{20}$ (over the length of the constructed wetland). It is also observed in the literature [1,7-9] and confirmed in our experiments that the 
major portion of BOD removal occurs in a relatively short time period of Hydraulic retention time (HRT) or in other words, major BOD removal occurs in the part of constructed wetland near the Inlet zone. The flowing are reasons to consider the dynamic characteristic of Bio-decay rate in our model: (i) Inlet zone has greater availability of oxygen, as compared to rest of the bed; (ii) BOD load caused by suspended particles are mostly filtered out in this zone; (iii) The simpler compounds of the dissolved organic load are easily and rapidly oxidised by bacteria and as wastewater flows in the bed, more complex nature of organic waste remains to be oxidized; hence bio-decay rate decreases with the length of flow. The behaviour of change of bio-decay rate constant can be mathematically defined as:

$$
K(x)=\left(K-\frac{G x}{L}-\frac{2 H x}{L}+\frac{H x^{2}}{L^{2}}\right)
$$

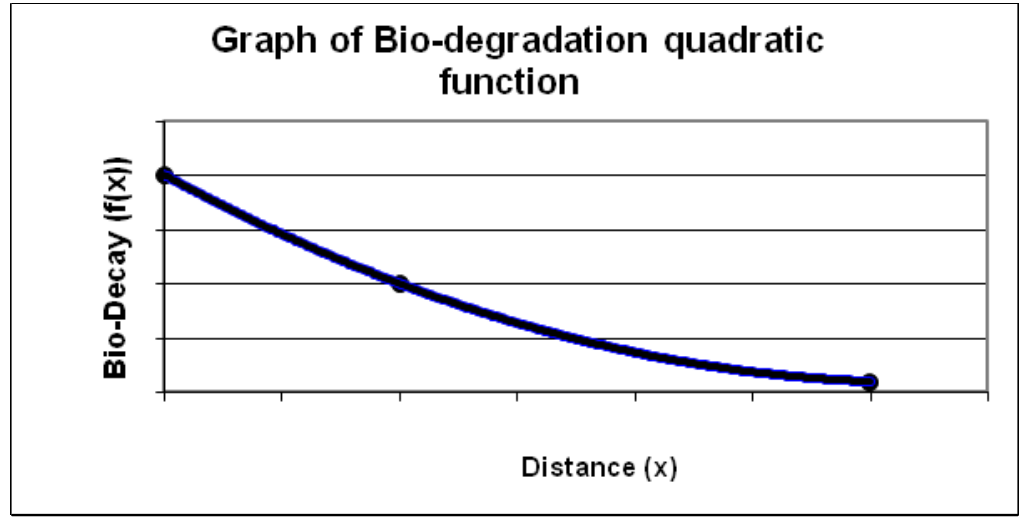

Figure 2: Bio-degradation quadratic function.

The above-mentioned Bio-degradation quadratic function $\mathrm{K}(\mathrm{x})$ satisfies the following conditions:

- $\mathrm{K}(\mathrm{x})$ is a decreasing function in the interval $0 \leq x<\left(L+\frac{G L}{2 H}\right)$

- The rate of change of bio-decay constant $\mathrm{K}$ decreases as the distance $\mathrm{x}$ increases.

where $\mathrm{H}$ and $\mathrm{G}$ are constant $>0$,

$\mathrm{L}$ is length of bed $>0$

$K$ is bio-decay rate and is $>\left(G+H+\frac{G^{2}}{4 H}\right)>0$

\subsection{Evapo-transpiration}

The impact of evapo-transpiration is more prominent in horizontal flow $\mathrm{CW}$, as compared to vertical flow $\mathrm{CW}$ [3]. The water loss due to evapo-transpiration is 
significant and should be considered for design and simulation of constructed wetland in arid climates. It is also an important factor during the warm summer months in other geographical locations [1, 6, 8, 9]. Evaporative water losses in the summer months considerably decrease the water volume in the system therefore; the concentration of the pollutants remaining in the system tends to increase even in the case of high efficiency treatment on mass-removal basis. It can be concluded that the pore velocity in the constructed wetland is not constant and decreases linearly as flow travels from the inlet to the outlet zone. Hence the pore velocity can be mathematically defined as

$$
V(x)=\left(V-\frac{P x}{L}\right)
$$

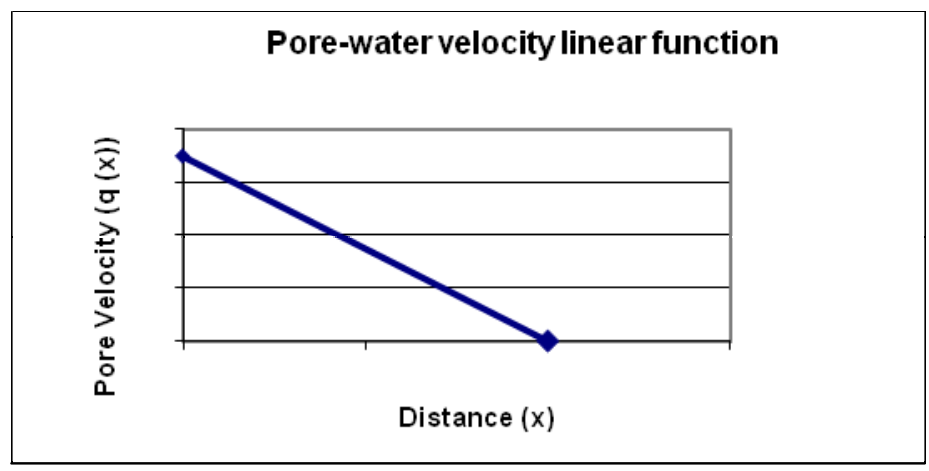

Figure 3: $\quad$ Pore-water velocity.

The above-mentioned pore-water velocity is a linear function and $\mathrm{V}(\mathrm{x})$ satisfies the following condition:

- $\quad$ At $\mathrm{x}=0, \mathrm{~V}(\mathrm{x})=\mathrm{V}$

- The rate of change of $\mathrm{V}(\mathrm{x})$ is constant always

- $\quad$ At $\mathrm{x}=\mathrm{L}, \mathrm{V}(\mathrm{x})=(\mathrm{V}-\mathrm{P})$

where, $\mathrm{V}$ is initial pore velocity and is $>\left(P+\frac{P G}{2 H}\right)>0$

$\mathrm{H}$ and $\mathrm{G}$ are constant $>0$,

$\mathrm{L}$ is length of bed $>0$

\subsection{Temperature}

It is evident that temperature plays a major role in removal of organic matter from the effluent as shown by Arrhenius equation. The daily average air temperature during the study period was found to be in the range of 16 to $34^{\circ} \mathrm{C}$. The temperature values were taken from the local weather station located at Safdarjung, approximately six kilometres from the experimental site. In temperate and cold climates, porous media and plant roots keep the wastewater temperature in winter higher than the air temperature by $2-3^{0} \mathrm{C}[10]$, whereas in 
tropical and subtropical regions the air temperature can be taken as the effluent temperature. As in the case ET, here also the average value of temperature over the period of HRT is considered for simulation.

\subsection{Mathematical model development}

Consider one-dimensional the advection diffusion equation (ordinary linear differential equation of the second order with variable coefficients) in the following form:

$$
S \frac{d^{2} C}{d x^{2}}-V(x) \frac{d C}{d x}-K(x) C=r
$$

By including the values for $V(x)$ and $K(x)$ in above differential equation we get

$$
S \frac{d^{2} C}{d x^{2}}-\left(V-\frac{P x}{L}\right) \frac{d C}{d x}-\left(K-\frac{G x}{L}-\frac{2 H x}{L}+\frac{H x^{2}}{L^{2}}\right) C=r
$$

or

$$
S \frac{d^{2} C}{d x^{2}}-(V-a x) \frac{d C}{d x}-\left(K-g x+h x^{2}\right) C=r
$$

subject to the following boundary conditions:

$$
\text { when } x=0, \mathrm{C}(0)=\mathrm{C}_{0} \text { and }\left(\frac{d^{2} C}{d x^{2}}\right)_{x=0}=0
$$

i.e. $\frac{d C}{d x}$ has maximum value at $x=0$ and $\frac{d^{3} C}{d x^{3}}$ is negative at $x=0$

Till now most of the researchers have taken the values of $\mathrm{K}(\mathrm{x})$ and $\mathrm{V}(\mathrm{x})$ as positive constants and $r$ as zero, then the above differential equation (3.4) will change into a differential equation with constant coefficients, whose solution is called complementary function [11].

The coefficients multiplying $\mathrm{d}^{2} \mathrm{C} / \mathrm{dx}^{2}$ and $\mathrm{dC} / \mathrm{dx}$ are functions of $\mathrm{x}, \mathrm{S}, \mathrm{V}, \mathrm{a}, \mathrm{K}$, $\mathrm{g}$, and $\mathrm{h}$. Therefore to obtain a higher degree of accuracy of a particular solution of differential equation (3.4), the method of Ferdinand George Frobenius (1873) [German mathematician, (1849-1917)] was used for power series solution of the considered boundary value problem (3.5) and (3.6).

\subsubsection{Frobenius method}

Since the coefficient multiplying $\mathrm{d}^{2} \mathrm{C} / \mathrm{dx}^{2}$ in the differential equation (3.4) is equal to $\mathrm{S}$, a nonzero constant, polynomials $V(x), K(x)$ are analytic everywhere, therefore $\mathrm{x}=0$ is an ordinary point. Hence according to Fuchs's theorem, at least one power series solution will be obtained when we apply Frobenius method. The derivation of the solution is not shown because of space restrictions. The solution is shown in (3.4): 


$$
\begin{aligned}
& C(x)=C_{0}+M x+\left[\frac{M(K-a)-C_{0} g}{S}\right] \frac{x^{3}}{6}+\left[\frac{M(K V-a V-2 g S)-C_{0}(g V-2 h S)}{S^{2}}\right] \frac{x^{4}}{24}+ \\
& {\left[\frac{\mathrm{M}\left(\mathrm{V}^{2} \mathrm{~K}+3 \mathrm{a}^{2} \mathrm{~S}+\mathrm{K}^{2} \mathrm{~S}+6 \mathrm{hS} \mathrm{S}^{2}-\mathrm{V}^{2} \mathrm{a}-2 \mathrm{gSV}-4 \mathrm{SKa}\right)-\mathrm{C}_{0}\left(\mathrm{~V}^{2} \mathrm{~g}+\mathrm{SKg}-2 \mathrm{hSV}-3 \mathrm{aSg}\right)}{\mathrm{S}^{3}}\right] \frac{x^{5}}{120}+\ldots}
\end{aligned}
$$

where

$$
\mathrm{M}=\left(\frac{d C}{d x}\right)_{x=0}=-\left[\frac{r+C_{0} K}{V}\right]
$$

It can be shown that

$$
\left(\frac{-L r K+\operatorname{Pr}-C_{0} K^{2} L+P C_{0} K}{(G+2 H) C_{0}}\right)<V
$$

Under the condition (3.9) we can say that the value of $\left(\frac{d C}{d x}\right)_{x=0}$ is maximum and its value is given by (3.8).

\section{Results and discussion}

The proposed simulation model for a Horizontal Flow Constructed Wetland (HFCW) system is a model that simulates the interval-by-interval operation of the system with specified inflows quality and quantity at all locations during each interval, specified system characteristics and specified operating rules. Under the given operating conditions, the performance of a HFSSCW system may be evaluated by analysing the computed time sequence of discharges, BOD, TKN, bio decay rate, etc. The procedure can be repeated for a number of inflow sequences to arrive at a statistical measure of the system.

Table 1: Different simulation conditions used in the study.

\begin{tabular}{|l|l|l|}
\hline Simulation & Remarks & Mathematical Equation \\
\hline Plug Flow & $\begin{array}{l}\text { Constant nature of } \\
\text { flow (Plug flow } \\
\text { assumption) } \\
\begin{array}{l}\text { Constant value of bio- } \\
\text { decay with-in the bed) }\end{array}\end{array}$ & $C_{\text {out }}=C_{\text {in }} e^{\left(-k_{v} \tau\right)}$ \\
\hline SIM 1 & $\begin{array}{l}\text { Dynamic nature of } \\
\text { flow } \\
\text { Dynamic value of bio- } \\
\text { decay with-in the bed }\end{array}$ & $S \frac{d^{2} C}{d x^{2}}-(V-a x) \frac{d C}{d x}-\left(K-g x+h x^{2}\right) C=r$ \\
\hline
\end{tabular}

Equation (3.7) was used to develop a computer simulation programme in $\mathrm{C}^{++}$ of Microsoft visual studio 2005. The data generated by conducted series of experimental studies on pilot plant of a horizontal flow sub-surface constructed wetland in India has been used for validation. 
Simulation was performed under plug flow and the advection diffusion equation with four different conditions to study the significance of evapotranspiration and dynamic nature of bio-decay.

The data generated by conducting series of experimental studies on pilot plant of horizontal flow sub-surface constructed wetland located in India is used for validation purpose. Since there are two numbers of identical sizes SSCW in the pilot plant, the average values of intermittent and effluent samples from both $\mathrm{H} 1$ and $\mathrm{H} 2$ beds were considered for validation purpose.

The graph showing observed and predicted values of BOD for different operating conditions, see Figure 4, shows that SIM 1 follows the observed values of intermittent and effluent BOD more closely as compared to plug flow.

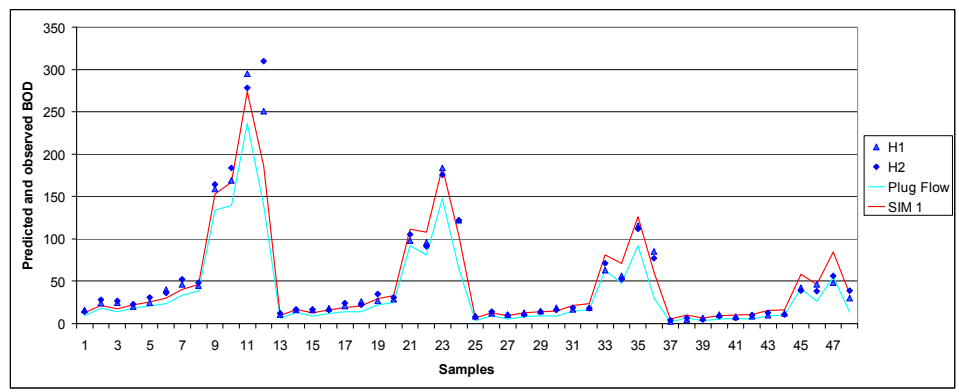

Figure 4: $\quad$ Observed and predicted values BOD.

\subsection{Error analysis}

Error analysis is an important tool for identifying the best-fit model. For this analysis 48 points (average values of $\mathrm{H} 1$ and $\mathrm{H} 2$ ) were used. The error analysis for various simulation conditions is shown in Table 2, which clearly shows lower error for the currently proposed model. The proposed model can predict reactive solute concentration more accurately than the plug flow model. The average relative (\%) error observed in SIM 1 is 17.78 , whereas for the plug flow model the value is 29.62 .

Table 2: $\quad$ Errors between predicted and observed values.

\begin{tabular}{|l|lc|c|}
\hline Error & \multicolumn{1}{|c|}{ Plug Flow } & SIM 1 \\
\hline Max. Relative Error [\%] & $\left(\left(100\left(\mathrm{C}_{\mathrm{o}}-\mathrm{C}_{\mathrm{s}}\right) / \mathrm{C}_{\mathrm{o}}\right)^{2}\right)^{0.5}$ & 62.57 & 66.80 \\
\hline Min. Relative Error [\%] & $\left(\left(100\left(\mathrm{C}_{\mathrm{o}}-\mathrm{C}_{\mathrm{s}}\right) / \mathrm{C}_{\mathrm{o}}\right)^{2}\right)^{0.5}$ & 2.88 & 0.10 \\
\hline & $\mathrm{Avg}\left(\left(100\left(\mathrm{C}_{\mathrm{o}^{-}}\right.\right.\right.$ & 29.62 & 17.78 \\
\hline
\end{tabular}

\section{Conclusions}

First order plug flow regime cannot adequately represent the treatment phenomenon in SSCW. A new approach based on the advection diffusion equation model, was developed taking care of the dynamic nature of bio-decay 
within the length of bed and dynamic value of velocity because of evapotranspiration/rainfall. The value of bio-decay is considered as a function of organic loading strength rather than as a constant value for all organic loading.

The simulation model, based on the dynamic behaviour of bio-decay rate and velocity approach was found to be superior in terms of predicting the performance of SSCW. Average relative error for proposed simulation model is $17.78 \%$ as compared to $29.62 \%$ for first order plug flow regime. The coefficient of correlation for the current model is $\mathrm{R}^{2}=0.943$ compared to $\mathrm{R}^{2}=0.923$ for plug flow model. The proposed simulation model can be effectively used for the optimization of the surface area of the SSCW and its geometry.

The developed mathematical model can be effectively used for optimum design of CW under tropical and subtropical climates.

\section{References}

[1] Reed, S.C., Crites, R.W., Middlebrooks, E.J., 1998. Natural systems for waste management and treatment. McGraw-Hill, New York, NY, p. 433.

[2] Ayaz, S.C., Akca, I., 2000. Treatment of wastewater by constructed wetland in small settlements. Water Sci. Technol. 41 (1), 69-72.

[3] Ahmed, Sirajuddin, 2000. Application of root zone treatment system for dairy wastewater at mother dairy. In: Proceedings of the International Conference on Constructed Wetlands for Wastewater Treatment in Tropical and Subtropical Region Anna University, Channai, India.

[4] Billore, S.K., Singh, N., Sharma, J.K., Dass, P., Nelson, R.M., 1999. Horizontal subsurface flow gravel bed constructed wetland with Phragmites karka in Central India. Water Sci. Technol. 40 (3), 163-171.

[5] APHA, 1998. Standard Methods for the Examination of Water and Wastewater, 20th ed. American Public Health Association/American Water Works Association Water Environment Federation, Washington, DC, USA.

[6] Kadlec, R.H., Knight, R.L., 1996. Treatment Wetlands. CRC Press, Boca Raton, FL, USA

[7] Kadlec, R.H., 2000. The inadequacy of first-order treatment wetland models. Ecol. Eng. 15 (1/2), 105-119.

[8] EPA, 1993. Constructed wetlands for wastewater treatment and wild life habitat: 17 Case Studies. EPA832-R-93-005.

[9] EPA, 1993. Subsurface flow constructed wetlands for wastewater treatment, a technology assessment. EPA 832-R-93-008, Office of Water, Washington, DC.

[10] Hiley, Peter D; (1995) The reality of sewage treatment using wetlands, water science technology, vol. 32, No. 3, 329-338

[11] Shulin Chan, Wang, Guang Te and Xue S.K., Modeling BOD Removal in Constructed wetlands win mixing cell method ASCE Journal of Environmental Engineering Vol 125 M01, pp 64-71. 